\title{
Cerebral blood flow and metabolism in children with severe head injury. Part 1: relation to age, Glasgow coma score, outcome, intracranial pressure, and time after injury
}

\author{
P M Sharples, A G Stuart, D S F Matthews, A Aynsley-Green, J A Eyre
}

\begin{abstract}
Understanding the pathophysiology of paediatric head trauma is essential for rational acute management. It has been proposed that the response to severe head injury in children differs from that in adults, with increased cerebral blood flow (cerebral hyperaemia) representing the most common cause of raised intracranial pressure, but this has recently been disputed. The relation between the pathophysiological response and time after injury has not been defined in children.
\end{abstract}

This paper describes 151 serial measurements of cerebral blood flow, arteriojugular venous oxygen difference $\left(\mathrm{AJ} \mathrm{VDo}_{2}\right)$, and cerebral metabolic rate for oxygen $\left(\mathrm{CMRO}_{2}\right)$ that were performed in 21 children with severe head injury, mean age 8 (range 2-16) years, Glasgow coma score $\leqslant 8$.

Absolute cerebral hyperaemia was uncommon, only $10(7 \%)$ of the 151 cerebral blood flow values being at or above the upper limit of the range published in normal children. There was an inverse correlation between cerebral blood flow and intracranial pressure. $(r=-0 \cdot 24$, $p=0.009)$. Contrary to the widespread assumption that cerebral metabolic rate in patients with head injury is always low, $\mathrm{CMRO}_{2}$ was initially within the normal range in $17 / 21(81 \%)$ children. Both $\mathrm{CMRO}_{2}$ and $\mathrm{AJVDO}_{2}$ fell significantly between the first and third days after injury. There was a non-significant rise in cerebral blood flow over time.

These data represent the first evidence that the temporal change in cerebral metabolic rate reported in experimental models of traumatic brain injury also occurs in patients with head injury. The changes in the pathophysiological response over time suggest that the management may need to be modified accordingly. If cerebral metabolic rate and cerebral oxygen extraction are maximal shortly after injury in children with severe head injury then the children are most likely to sustain secondary damage during this period.

(F Neurol Neurosurg Psychiatry 1995;58:145-152)

Keywords: head injury; cerebral blood flow; intracranial pressure.
Head injury is the most common cause of death and long term morbidity in children over one year of age. ${ }^{12}$ An understanding of the underlying pathophysiology of traumatic encephalopathy is fundamental to improving its acute management. Most clinical studies have involved mainly adults, however, with children representing only a small proportion of the study populations.

It has been proposed that the pathophysiology of paediatric head injury differs from that in adults, with increased cerebral blood flow (cerebral hyperaemia) occurring more often in children. This hypothesis was first advanced by Bruce $e t a l$, who suggested that in children increased cerebral blood flow led to increased cerebral blood volume and thus to raised intracranial pressure. These authors recommended that comatose children with head injury should be electively hyperventilated to reduce cerebral blood flow ${ }^{3-5}$ and that mannitol should be avoided, ${ }^{5}$ as this might increase cerebral blood flow by decreasing blood viscosity. ${ }^{6}$

The recommendations advanced by Bruce et $a l^{3-5}$ have been widely published in books and review articles. ${ }^{5-9} \mathrm{~A}$ recent study of cerebral blood flow in children and young adults with head injury, however, failed to support their hypothesis, Muizelaar et al concluding that absolute cerebral hyperaemia is uncommon in children with severe head injury. ${ }^{10}$

The uncertainty concerning the pathophysiology of paediatric head injury extends to cerebral metabolism as well as cerebral blood flow. Swedlow et al reported increased cerebral metabolic rate and appropriately increased cerebral blood in some of the children they studied. ${ }^{11}$ By contrast, Muizelaar et al concluded that cerebral metabolic rate was always depressed..$^{10}$ No previous study has investigated in detail the relation between cerebral blood flow and cerebral metabolic rate and time after head injury in children.

The importance of defining the nature of the changes in cerebral blood flow and metabolism that occur after severe head injury in children is emphasised by the high incidence of ischaemic brain damage found in neuropathological studies of the brains of children with fatal head injury. ${ }^{20}$

The aims of this study were: firstly, to measure cerebral blood flow and cerebral metabolism serially in children who had a severe head injury and to define their relation to age, severity of head injury, time after injury, and outcome; and secondly, to examine the 
hypothesis that raised intracranial pressure in children with head injury is the result of increased cerebral blood flow.

\section{Patients and methods PATIENTS}

Ethical approval for the study was granted by the local ethics committee and informed written consent was obtained from the parent or guardian. The study was performed in 21 children (mean age 8 (range 2-16) years) who had sustained a severe head injury and were receiving intensive care, including assisted ventilation (table). The criterion for admission to the study was a Glasgow coma score ${ }^{13}$ $\leqslant 8 .{ }^{14}$ In children younger than 4 years, the adaptation of the Glasgow coma score described by James and Trauner was used. ${ }^{15}$ The median Glasgow coma score was 6 (range 3-8).

\section{MANAGEMENT}

The clinical care of the children remained the responsibility of the admitting neurosurgical and anaesthetic teams. All were artificially ventilated. The aim of ventilation was to maintain $\mathrm{PaCO}_{2}$ between $3.5-4.5 \mathrm{kPa}$, unless there was a sustained rise in intracranial pressure when $\mathrm{PaCO}_{2}$ was maintained below $3.5 \mathrm{kPa}$. Crystalloid fluids were restricted to $50 \%$ of normal requirements but colloidal solutions were given as necessary to maintain normal blood pressure. Nineteen children received muscle relaxants (vecuronium 50-100 $\left.\mu \mathrm{g} \cdot \mathrm{kg}^{-1} \cdot \mathrm{h}^{-1}\right)$ and fentanyl (1.0-2.0 $\left.\mu \mathrm{g} \cdot \mathrm{kg}^{-1} \cdot \mathrm{h}^{-1}\right)$; these agents were omitted in two cases (cases 20 and 21) to facilitate neurological assessment.

Monitoring of intracranial pressure was performed in 18 patients (86\%) (see later). Rises in intracranial pressure (defined as intracranial pressure $>20 \mathrm{~mm} \mathrm{Hg}$ for more than 10 minutes) ${ }^{16}$ were treated either by giving mannitol $\left(0.5 \mathrm{~g} . \mathrm{kg}^{-1}\right)$ or by increasing the rate of ventilation. Steroids were not given. In 17 children (81\%), two channels of an EEG were recorded continuously with a miniaturised EEG (Oxford Medilog 9000) and the tape was reviewed at eight-hourly intervals for evidence of seizure activity. ${ }^{17}$ Three children had seizures; two were treated with thiopentone (cases 1 and 5) and one with phenytoin (case 7).

Neurological outcome was scored after discharge with an adaptation of the scales employed by Berger et al ${ }^{18}$ and Tasker et al..$^{19}$ The mean time between admission and assessment was 15 (range 6-24) months. Outcome was classed as "poor" if the child died or survived with either a major neurological handicap (spastic tetraparesis, hemiparesis, uncontrolled epilepsy) or a major cognitive handicap (defined as severe enough to necessitate attendance at a special school); as "moderate" if the child survived with a less severe degree of neurological impairment, controlled epilepsy, or behaviour disturbance, and as "good" if the child had resumed preinjury activities with no neurological deficit or apparent change in personality or school performance.

\section{METHODS}

Serial measurements of cerebral blood flow and the cerebral metabolic rate for oxygen $\left(\mathrm{CMRO}_{2}\right)$ were made if possible at least once a day while the patient was receiving neurointensive care. Each measurement was performed when the patient's condition was stable.

\section{Measurement of cerebral blood flow}

Global cerebral blood flow was measured by the Kety Schmidt technique, with $10 \%$ nitrous oxide as the inert tracer. ${ }^{20} \mathrm{~A}$ detailed description of our method has been published. ${ }^{21}$ The estimate of error of the method was $1.58 \%$ with $95 \%$ confidence limits of $1 \cdot 02-2 \cdot 88 \% .^{21}$ Thus the measured values are likely to lie within $\pm 3 \%$ of the putative true value. $^{21}$

The results for cerebral blood flow are reported uncorrected for arterial $\mathrm{PCO}_{2}$.

Details of the 21 children with severe head injury

\begin{tabular}{|c|c|c|c|c|c|c|c|c|}
\hline Case & $\begin{array}{l}\text { Age } \\
\text { (y) }\end{array}$ & Sex & GCS & $\begin{array}{l}\text { Time of } 1 \text { st } \\
\text { measurement }\end{array}$ & $I C P$ & $\begin{array}{l}\text { Symbol (as } \\
\text { used in figs) }\end{array}$ & $\begin{array}{l}C T \\
\text { appearance }\end{array}$ & Outcome \\
\hline $\begin{array}{l}1 \\
2 \\
3 \\
4 \\
5 \\
6 \\
7 \\
8 \\
9 \\
10 \\
11 \\
12 \\
13 \\
14 \\
15 \\
16 \\
17 \\
18 \\
19 \\
20 \\
21\end{array}$ & $\begin{array}{r}9 \\
16 \\
16 \\
2 \\
3 \\
12 \\
8 \\
2 \\
2 \\
3 \\
5 \\
6 \\
7 \\
10 \\
4 \\
7 \\
8 \\
9 \\
12 \\
13 \\
15\end{array}$ & $\begin{array}{l}\mathrm{M} \\
\mathrm{F} \\
\mathrm{M} \\
\mathrm{M} \\
\mathrm{M} \\
\mathrm{F} \\
\mathrm{M} \\
\mathrm{M} \\
\mathrm{M} \\
\mathrm{F} \\
\mathrm{M} \\
\mathrm{M} \\
\mathrm{M} \\
\mathrm{M} \\
\mathrm{M} \\
\mathrm{M} \\
\mathrm{F} \\
\mathrm{M} \\
\mathrm{M} \\
\mathrm{M}\end{array}$ & $\begin{array}{l}6 \\
8 \\
7 \\
8 \\
6 \\
4 \\
6 \\
8 \\
8 \\
6 \\
4 \\
8 \\
6 \\
7 \\
3 \\
8 \\
4 \\
6 \\
4 \\
4 \\
3\end{array}$ & $\begin{array}{l}13 \cdot 5 \\
10 \\
26 \\
20 \cdot 5 \\
8 \\
9 \\
19 \\
16 \cdot 5 \\
44 \\
13 \\
38 \cdot 5 \\
12 \\
50 \\
57 \cdot 5 \\
7 \cdot 3 \\
11 \\
15 \\
8 \\
22 \\
8 \\
6\end{array}$ & $\begin{array}{l}\mathbf{Y} \\
\mathbf{Y} \\
\mathbf{Y} \\
\mathbf{Y} \\
\mathbf{Y} \\
\mathbf{Y} \\
\mathbf{Y} \\
\mathbf{Y} \\
\mathbf{Y} \\
\mathbf{Y} \\
\mathbf{Y} \\
\mathbf{Y} \\
\mathbf{Y} \\
\mathbf{Y} \\
\mathbf{Y} \\
\mathbf{Y} \\
\mathbf{Y} \\
\mathbf{Y} \\
\mathbf{N} \\
\mathbf{N} \\
\mathbf{N}\end{array}$ & 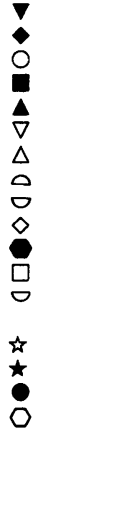 & $\begin{array}{l}\text { Diffuse swelling } \\
\text { Diffuse swelling } \\
\text { Focal contusion/SDH } \\
\text { Focal contusion } \\
\text { Focal contusion } \\
\text { Diffuse swelling } \\
\text { Diffuse swelling } \\
\text { Biffontal contusions } \\
\text { Left EDH } \\
\text { DAI } \\
\text { Diffuse swelling/SDH } \\
\text { DAI } \\
\text { Normal } \\
\text { Right frontal haematoma } \\
\text { Diffuse swelling/DAI } \\
\text { Biffontal contusions } \\
\text { Diffuse swelling } \\
\text { Diffuse swelling/DAI } \\
\text { Normal } \\
\text { Diffuse swelling/DAI } \\
\text { Multiple contusions }\end{array}$ & $\begin{array}{l}\text { Good } \\
\text { Good } \\
\text { Good } \\
\text { Good } \\
\text { Good } \\
\text { Good } \\
\text { Moderate } \\
\text { Moderate } \\
\text { Moderate } \\
\text { Moderate } \\
\text { Moderate } \\
\text { Moderate } \\
\text { Moderate } \\
\text { Moderate } \\
\text { Died } \\
\text { Died } \\
\text { Poor } \\
\text { Poor } \\
\text { Poor } \\
\text { Poor } \\
\text { Died }\end{array}$ \\
\hline
\end{tabular}

GCS = Glasgow coma score; ICP = intracranial pressure; $\mathrm{Y}=$ monitored; $\mathrm{N}=$ not monitored; SDH = subdural haematoma; $\mathrm{EDH}=$ extradural haematoma; $\mathrm{DAI}=$ diffuse axonal injurv. 
Measurement of cerebral metabolic rate for oxygen At the end of each measurement of cerebral blood flow, arterial and superior jugular venous bulb blood samples $(0.5 \mathrm{ml})$ were obtained. Blood gas analysis was performed immediately with a Radiometer analyser (Corning 1312); the oxygen saturation and haemoglobin concentration were measured with a Co-Oximeter (Corning 2500) and oxygen content calculated according to the equation $^{22}$ :

$\mathrm{O}_{2}$ content $=\mathrm{Hb} \times \mathrm{O}_{2}$ sat $\times 1.39+\left(0.023 \times \mathrm{PaO}_{2}\right)$

where $\mathrm{Hb}$ is the haemoglobin concentration, $\mathrm{O}_{2}$ sat is the oxygen saturation and $\mathrm{PaO}_{2}$ is the arterial partial pressure of oxygen.

The cerebral metabolic rates for oxygen $\left(\mathrm{CMRO}_{2}\right)$ were calculated from the equation $^{2021}$ :

$$
\mathrm{CMRO}_{2}=\mathrm{CBF} \times(\mathrm{A}-\mathrm{V})
$$

where $\mathrm{CBF}$ is cerebral blood flow, and $\mathrm{A}$ and $\mathrm{V}$ are the arterial and venous oxygen concentrations.

\footnotetext{
Figure 1 Mean value and range of $(A)$ cerebral blood flow (CBF); (B) $\mathrm{CMRO}_{2}$; (C) $\mathrm{AFVDO}$ for each of the 21 patients in relation to age. The shaded part of each graph represents the range reported in normal children by Settergen, et al. ${ }^{24}$ There was no correlation between age and mean $C B F$

$(r=-0.18, p=0.43)$ mean $\mathrm{CMRO}_{2}(r=0 \cdot 24$, $p=0 \cdot 29)$, or mean

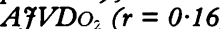
$p=0.48)$.
}

\section{Measurement of intracranial pressure}

Intracranial pressure was monitored in 18 patients; in five children via a fluid filled ventricular catheter connected to an externally mounted pressure transducer (ViggoSpectramed, Swindon, UK) and in 13, by a subarachnoid catheter with a Camino transducer on its tip. ${ }^{23}$ The wave form was displayed continuously on a monitor (Simonsen and Weel Monitor, System 8000, Triscope). The mean intracranial pressure was recorded at the commencement of each measurement of cerebral blood flow and metabolism.

\section{Results}

A total of 151 measurements of cerebral blood flow, arteriojugular venous oxygen content $\left(\mathrm{AJVDO}{ }_{2}\right)$, and $\mathrm{CMRO}_{2}$ were performed in the 21 children. The mean number of cerebral blood flow measurements performed in each patient was seven (range 1-21) and the mean duration of each study was 69 (range 4-196) hours (table).

In 10 children (48\%) the first measurement was performed within 12 hours after injury and in $18(86 \%)$ within 24 hours. The median time between injury and the first measurement in all 21 children was 13.0 (range 5.75-50) hours. In the three children with intracranial haematomas (cases 3, 9, and 11), all the measurements of cerebral blood flow were performed after surgical evacuation of the haematoma.

One measurement was associated with EEG evidence of seizure activity and has been excluded from further analysis.

RELATION OF CEREBRAL BLOOD FLOW, $\mathrm{CMRO}_{2}$, AND $\mathrm{AJNDO}_{2}$ TO AGE, GLASGOW COMA SCORE, AND OUTCOME

Figure 1 shows the mean value and range of cerebral blood flow (fig $1 \mathrm{~A}$ ), $\mathrm{CMRO}_{2}$ (fig 1B), and $\mathrm{AJVDO}_{2}$ (fig 1C) for each of the 21 patients in relation to age. The values varied considerably, both within and between patients. There was no correlation between the age of the patient and mean cerebral blood flow $(r=-0.18, p=0.43)$, mean $\mathrm{CMRO}_{2} \quad(r=-0.24, \mathrm{p}=0.29)$, or mean $\mathrm{AJVDO}_{2}(r=0 \cdot 16, \mathrm{p}=0 \cdot 48)$.

Figure 2 illustrates the relation between the admission Glasgow coma scores and the initial measurement of cerebral blood flow (fig 2A), $\mathrm{CMRO}_{2}$ (fig 2B), and $\mathrm{AJVDO}_{2}$ (fig 2C) obtained in the 21 children. There was no correlation between cerebral blood flow and conscious level (fig 2A) $(r=0.04, p=0.88)$ but there was a significant relation between Glasgow coma score and $\mathrm{CMRO}_{2}$ (fig 2B) $(r=$ $0.43, \mathrm{p}=0.049)$ and $\mathrm{AJVDo}_{2}$ (fig 2C) $(r=$ $0.47, \mathrm{p}=0.03$ ).

The Glasgow coma scores obtained from the 14 children who had a good or moderate outcome (mean 6.60) were significantly higher than those obtained from the seven children who had a poor outcome (mean 4.6; Student's $t$ test, $\mathrm{p}=0.011$ ). In the first 24 hours, mean cerebral blood flow in patients who had a good or moderate outcome was 
Figure 2 Relation between the admission Glasgow coma scores and the initial measurement of (A) cerebral blood flow (CBF); (B) $C M \mathrm{RO}_{2}$; (C) $A 7 V \mathrm{DO}_{2}$ obtained in the 21 subjects. The shaded part of each graph represents the range reported in normal children by Settergen et al. ${ }^{24}$ There was no correlation between $C B F$ and conscious level $(r=0.04, p=0.88)$, but there was a significant relation between Glasgow coma score and $\mathrm{CMRO}_{2}$ $(r=0.43, p=0.04)$ and $\mathrm{AFVDO}_{2}(r=0.47$, $p=0.03$ )
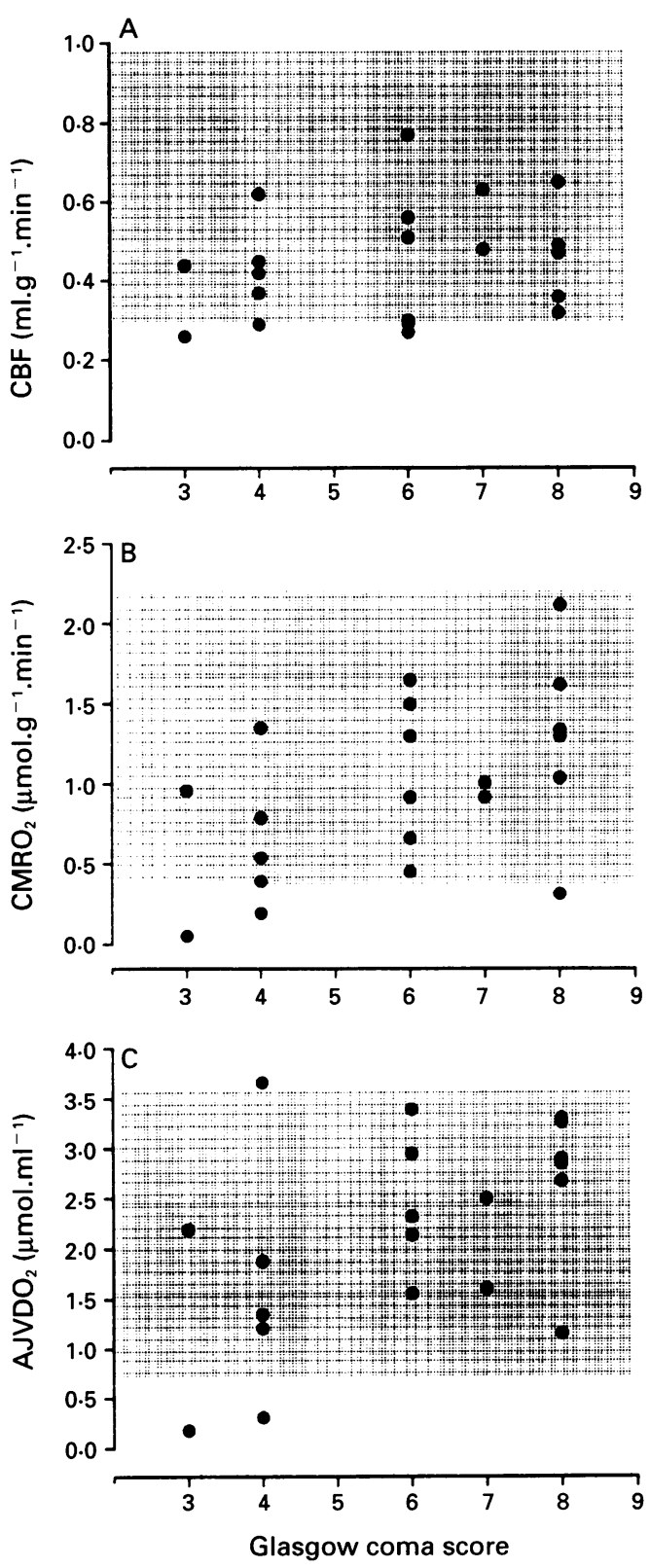

significantly higher than in those who had a poor outcome (Student's $t$ test, $\mathrm{p}=0.015$ ). Mean $\mathrm{CMRO}_{2}$ in the first 24 hours was also significantly higher in children who had a good or moderate outcome compared with those who had a poor outcome (Student's $t$ test, $p=0 \cdot 017$ ). After 24 hours, neither mean cerebral blood flow nor mean $\mathrm{CMRO}_{2}$ differed significantly between children who had good or moderate outcomes and children who had poor outcomes (Student's $t$ test, cerebral blood flow; $\left.\mathrm{p}=0.94 ; \mathrm{CMRO}_{2} ; \mathrm{p}=0.47\right)$.

RELATION OF CEREBRAL BLOOD FLOW, $\mathrm{CMRO}_{2}$, AND $\mathrm{AJVDO}_{2}$ TO RESULTS REPORTED IN NORMAL CHILDREN

The shaded portions of each graph in fig 1 represent the ranges obtained in normal children by Settergren et al. ${ }^{2124}$ For 17 of the study patients $(81 \%)$, mean cerebral blood flow and mean $\mathrm{CMRO}_{2}$ fell within the normal range; the mean $\mathrm{AJVDO}_{2}$ fell within the normal range in 20 patients $(95 \%)$. In the child

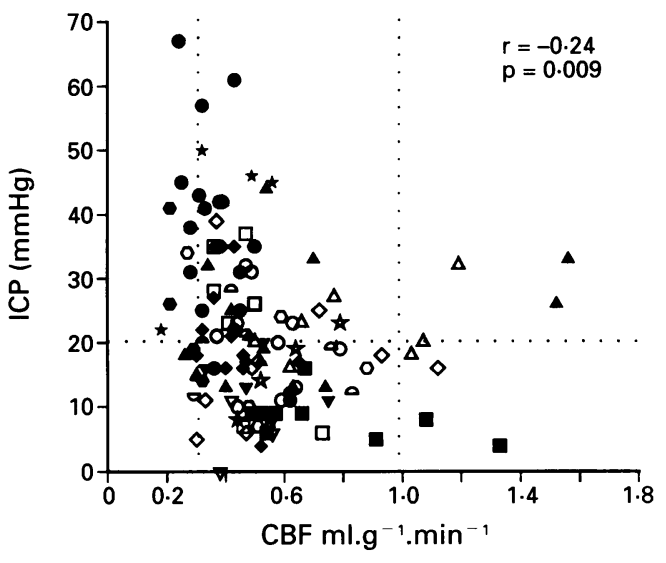

Figure 3 Relation between cerebral blood flow (CBF) and intracranial pressure (ICP) for the 122 measurements for which simultaneous results were available, excluding the result associated with a seizure. Each patient is represented by a different symbol. Overall, there was a significant inverse relation between $C B F$ and intracranial pressure $(r=-0.24, p=0.009)$. The vertical dotted lines represent the range of normal values for $C B F$ described by Settergen et al. ${ }^{24}$

(case 21) in whom mean $\mathrm{AJVDO}_{2}$ was very low, brain death tests subsequently proved positive. The EEG recording obtained from this patient was of low amplitude throughout, whereas the EEG recordings obtained from the other children at the time of admission to the intensive care unit showed high voltage slow wave activity.

Values for cerebral blood flow tended to be low, $116 / 150(77 \%)$ being below the mean cerebral blood flow value reported in normal children ${ }^{21}{ }^{24}$ and only $9 / 150(6 \%)$ being at or above the upper limit of the normal range. ${ }^{21} 24$ Despite the low cerebral blood flow results, $\mathrm{AJVDO}_{2}$ values also tended to be low, $121 / 150$ $(81 \%)$ falling below the mean $\mathrm{AJVDO}_{2}$ value reported in normal children and only $29 / 150$ $(19 \%)$ were above the normal mean. ${ }^{21}{ }^{24}$ Only three $\mathrm{AJVDO}_{2}$ values were above the upper limit of the normal range. ${ }^{21} 24$

\section{RELATION OF CEREBRAL BLOOD FLOW TO} INTRACRANIAL PRESSURE

Figure 3 illustrates the relation between cerebral blood flow and intracranial pressure for the 122 measurements for which simultaneous results were available, excluding the result associated with a seizure. Overall, there was a significant inverse relation between cerebral blood flow and intracranial pressure $(r=-0.24, \mathrm{p}=0.009)$. In only three results $(2 \%)$, obtained from two children, were increased intracranial pressures $(>20 \mathrm{~mm} \mathrm{Hg}$ ) associated with cerebral blood flow above the upper limit of the normal range. ${ }^{1016}$

To investigate further the nature of the relation between cerebral blood flow and intracranial pressure, the 122 cerebral blood flow measurements were divided into two groups, according to whether or not intracranial pressure at the time of the measurement was significantly increased $(>20 \mathrm{~mm} \mathrm{Hg}){ }^{10}$ Values for cerebral blood flow associated with significantly raised intracranial pressure 
Figure 4 Relation between time after injury and $(A)$ cerebral blood flow (CBF); (B) $\mathrm{CMRO}_{2}$ (C) $\mathrm{AFVDO}_{2}$ for all 21 subjects. The shaded part of each graph represents the range reported in normal children by Settergen et al 24
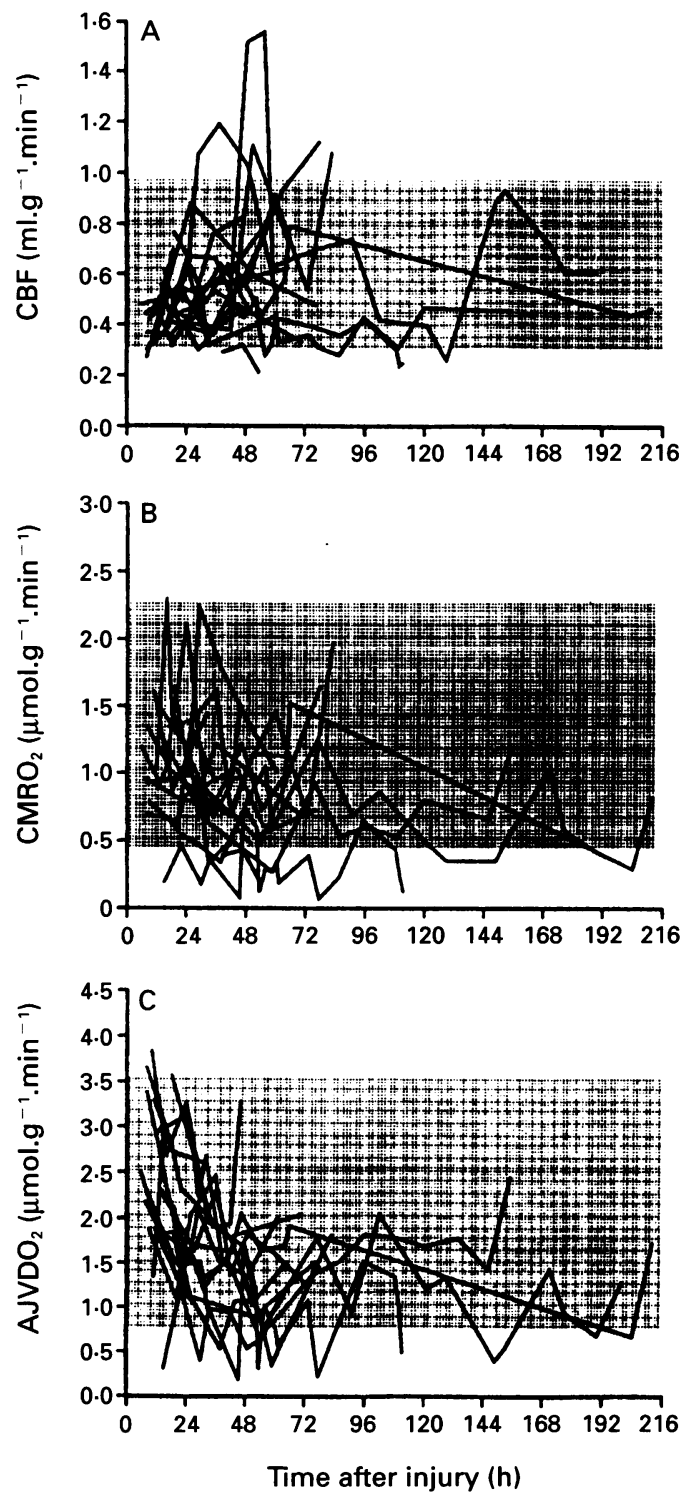

(>20 mm Hg; $\mathrm{n}=56$, mean cerebral blood flow 0.47 (range $0.18-1.56) \mathrm{ml} . \mathrm{g}^{-1} \cdot \mathrm{min}^{-1}$ ), were significantly lower than those associated with lower values for intracranial pressure ( $<20 \mathrm{~mm} \mathrm{Hg} ; \mathrm{n}=66$, mean cerebral blood flow 0.57 (range $0.26-1.33$ ) $\mathrm{ml}^{-1} \cdot \mathrm{min}^{-1}$; Student's $t$ test, $\mathrm{p}=0.037$ ).

RELATION OF CEREBRAL BLOOD FLOW, $\mathrm{CMRO}_{2}$, AND AJVDO 2 TO TIME AFTER INJURY

Figure 4 shows the relations between time after injury and cerebral blood flow, $\mathrm{CMRO}_{2}$, and $\mathrm{AJVDO}_{2}$. Fourteen patients had measurements performed on the first, second, and third days after injury. The cerebral blood flow increased slightly between the first and third days after injury in these patients, but the difference in the results did not achieve statistical significance (fig 4A); (paired $t$ test, $\mathrm{p}=0.06$ ). By contrast, $\mathrm{CMRO}_{2}$ and $\mathrm{AJVDo}_{2}$ fell significantly between the first and third days after injury (fig 4B and C; paired $t$ test, $\mathrm{CMRO}_{2} ; \mathrm{p}=0.001 ; \mathrm{AJVDO}_{2} ; \mathrm{p}=0.0003$ ). In a number of the children who survived, $\mathrm{CMRO}_{2}$ and $\mathrm{AJVDO}_{2}$ tended to rise again towards the end of the period of intensive care (fig 4B and C).

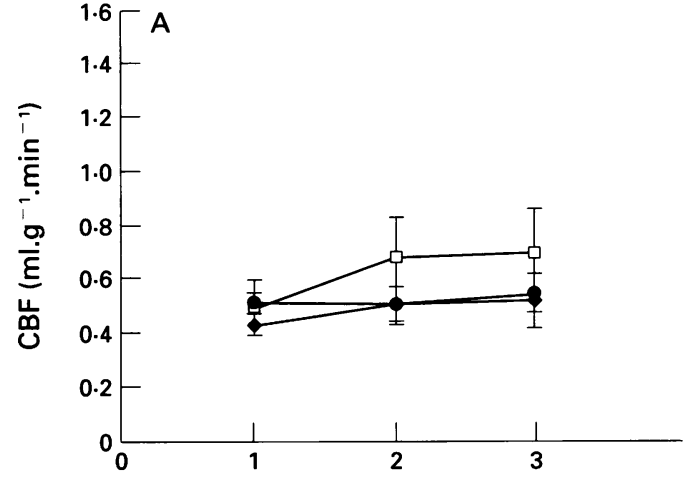

Time after injury (days)
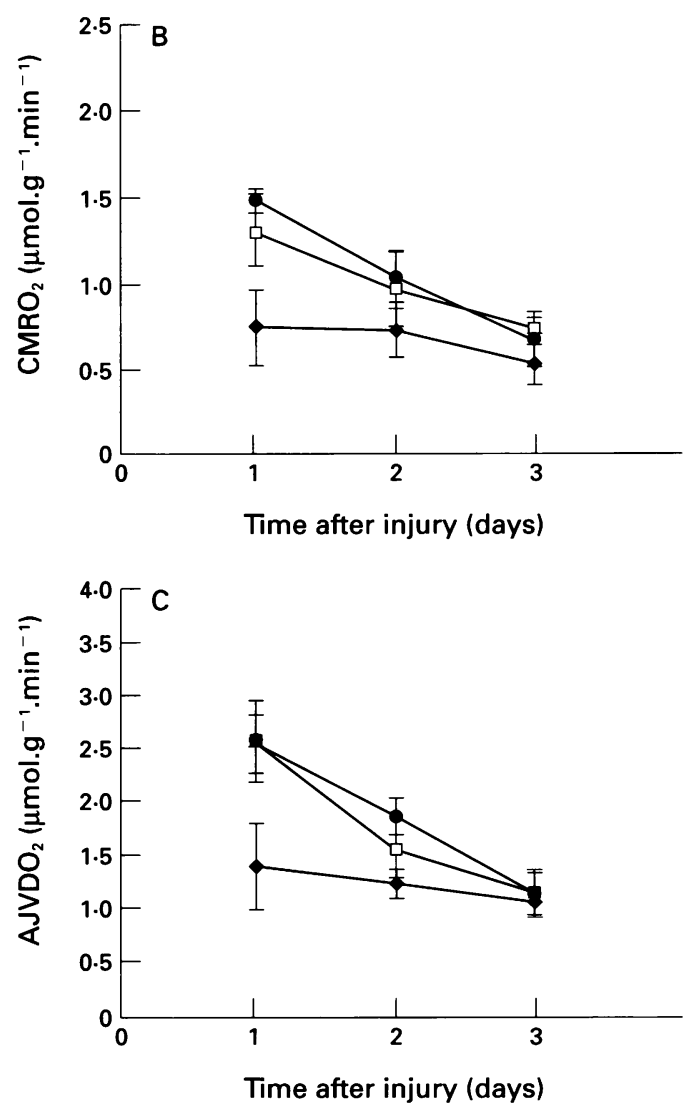

Figure 5 Relation between time after injury and $(A)$ cerebral blood flow (CBF); (B) CMRO ${ }_{2}$; (C) $\mathrm{AFVDO}_{2}$ according to admission Glasgow coma score. The means of the results obtained from patients with an admission Glasgow coma score of 3 or 4 are represented by closed diamonds $(n=7)$; the mean of the results obtained from patients with an admission Glasgow coma score of 5 or 6 by open squares $(n=6)$; and the mean of the results obtained from patients with admission Glasgow coma scores of 7 or 8 by closed circles $(n=8) . \mathrm{CMRO}_{2}$ and $\mathrm{AfVDO}_{2}$ fell over time in patients with Glasgow coma scores 5-8, but remained low throughout in patients with admission Glasgow coma scores of 3 or 4 . Error bars are SEM.

The fall in $\mathrm{CMRO}_{2}$ and $\mathrm{AJVDO}_{2}$ occurred in patients with primary injuries of varying severity, as evidenced by admission Glasgow coma scores that ranged from 3-8. The fall was much less pronounced in the most severely injured children (Glasgow coma scores 3 or 4 ), in whom both $\mathrm{CMRO}_{2}$ and $\mathrm{AJVDO}_{2}$ were often very depressed from the time of the first measurement (fig $5 \mathrm{~B}$ and C). 


\section{Discussion}

The results of this study do not support the proposal that children have raised cerebral blood flow after severe head injury. Instead, they confirm the findings of Muizelaar et al, ${ }^{10}$ who concluded that absolute cerebral hyperaemia is an uncommon finding in such patients. Only one child in the present study had cerebral blood flow values consistently above or in the upper part of the range reported in normal children. ${ }^{21} 24$ These findings are similar in nature to those previously reported in adults with severe head injury, ${ }^{25-28}$ and together with the lack of any relation between cerebral blood flow and age, suggest that there is no fundamental difference between adults and children in the pathophysiological response of cerebral blood flow to severe head injury.

In this study, raised intracranial pressure was associated with low, rather than increased, cerebral blood flow and thus does not support the hypothesis that raised intracranial pressure occurs as a result of excessive cerebral blood flow in children with head injury. ${ }^{3-5}$ The data support the conclusions of Muizelaar $e a^{a l^{10}}$ and suggest that it is unnecessary to avoid the use of mannitol in children with head injury.

Cerebral blood flow and $\mathrm{AJVDo}_{2}$ values in this study have been reported uncorrected for $\mathrm{PaCO}_{2}$, despite the fact that the study children were electively hyperventilated (mean $\mathrm{PaCO}_{2}$ 3.96 (range 2.1-5.5) $\mathrm{kPa}$. This was done because of the clinical and experimental evidence to show that if hyperventilation is prolonged beyond six hours, cerebral blood flow returns to normal despite persisting low $\mathrm{PaCO}_{2}{ }^{29-34}$ Correction for $\mathrm{PaCO}_{2}$ will therefore produce misleading results. Even if our cerebral blood flow results are corrected to a standard normal $\mathrm{PaCO}_{2}$ (39 $\mathrm{mm} \mathrm{Hg}$ ), however, there is still an inverse correlation between intracranial pressure and cerebral blood flow $(r=-0.19, \mathrm{p}=0.037)$.

The study by Graham et al has shown that generalised ischaemic damage is an almost universal finding in children with fatal head injury. ${ }^{12}$ It is a paradox, therefore, that the children in this study who died had very low cerebral metabolic rates and very low cerebral oxygen extraction, as indicated by the $\mathrm{AJVDO}_{2}$ values.

There are various possible explanations for the apparent discrepancy between the findings of this study and those of Graham et al. ${ }^{12}$ It is possible that as the measurements were intermittent, episodes of cerebral ischaemia may have occurred between measurements. ${ }^{35}$ The Kety Schmidt technique measures global cerebral blood flow and would not detect focal areas of ischaemia. Regional differences in cerebral blood flow in patients with head injury are usually minor, however, and superimposed on global changes in flow. $2536-38$ Neither of these explanations consider the issue of the change in the pathophysiological response to injury over time, which was the most striking finding of the study.

The decrease in $\mathrm{CMRO}_{2}$ and $\mathrm{AJVDo}_{2}$ with time after injury raises the possibility that cerebral metabolic rate might have been highest in these subjects immediately after the head injury. If cerebral blood flow is at its lowest at this time, ${ }^{39}$ then cerebral oxygen delivery might be insufficient for cerebral metabolic needs, resulting in secondary ischaemic brain damage. This study is the first to describe a fall in $\mathrm{CMRO}_{2}$ with time in patients with head injury although a recent paper by Bouma et al has described a pronounced fall in $\mathrm{AJVDO}_{2}$ over time in adults with head injury. ${ }^{39}$ There have been experimental studies in rats and cats, however, which have indicated that traumatic brain injury initially produces an increase in cerebral metabolic rate, which later gives way to a state of cerebral hypometabolism. 40-44 $^{-4}$

The changes in $\mathrm{CMRO}_{2}$ and $\mathrm{AJVDo}$ 佳 increasing time after injury cannot simply be attributed to sedative agents, because fentanyl, when given alone, has no appreciable effect on $\mathrm{CMRO}_{2}{ }^{45}$ Neither can they be attributed to changes in $\mathrm{PaCO}_{2}$ concentration, as even if $\mathrm{AJVDO}_{2}$ values are corrected to a standard $\mathrm{PaCO}_{2}$, a significant fall in $\mathrm{AJVDO}_{2}$ is still seen between the first and third days after injury (paired $t$ test, $\mathrm{AJVDO}_{2}, \mathrm{p}=0.001$ ). Correction for $\mathrm{PaCO}_{2}$ would not affect $\mathrm{CMRO}_{2}$ results.

If children with head injury are most at risk of sustaining ischaemic brain damage in the first few hours after injury then optimal management at this time may be of critical importance in determining eventual outcome. In particular, early hyperventilation to prevent raised intracranial pressure ${ }^{46}$ may run the risk of producing or exacerbating ischaemic damage in some patients. ${ }^{39}$

There is an alternative hypothesis that might explain the apparent discrepancy between the low incidence of metabolic evidence for cerebral ischaemia noted in clinical studies and the high incidence of ischaemic injury found on neuropathological examination in patients with fatal head injuries and that would also account for the finding that children who died or survived with significant handicap had the lowest cerebral metabolic rates. This hypothesis has been propounded by Yang $e t a l^{47}$ and Vink et $a l^{48}$ who proposed that cerebral trauma results in an impairment of brain mitochondrial respiratory chain function, thus preventing oxygen being utilised for aerobic metabolism. If this hypothesis is correct, then cerebral oxygen extraction and $\mathrm{CMRO}_{2}$ do not accurately reflect neural metabolic demands and cerebral ischaemic damage could occur despite a superabundant supply of oxygen to the brain. 3949

Disturbances of mitochondrial respiratory function have been extensively reported in animal models of cerebral ischaemia. ${ }^{50-52}$ In some cases the dysfunction has been noted to worsen over time. ${ }^{.5455}$ If a similar disturbance of mitochondrial function occurs after severe head injury, this could explain the low values for $\mathrm{CMRO}_{2}$ and $\mathrm{AJVDO}_{2}$, which were obtained in the most severely injured children in this study and might account in part for the 
fall in $\mathrm{CMRO}_{2}$ and $\mathrm{AJVDO}_{2}$ over time. A reversible inhibition of mitochondrial function might produce a fall in $\mathrm{CMRO}_{2}$ followed by a rise in $\mathrm{CMRO}_{2}$ concomitant with clinical improvement; irreversible inhibition might be associated with a persistently low $\mathrm{CMRO}_{2}$ and noticeable brain damage. In some experimental studies of hypoxic-ischaemic brain damage, poor neurological outcome has been directly correlated with persisting abnormalities of mitochondrial function. ${ }^{33-55}$ If mitochondrial dysfunction occurs after head injury then it would explain the finding of Robertson et al, who have reported cerebral lactate production, indicating anaerobic glycolysis, in association with cerebral metabolic rate and low oxygen extraction in patients with severe head injury. ${ }^{49}{ }^{56}$ Identification of the underlying processes might potentially lead to the eventual introduction of treatments to prevent or reverse such dysfunction ${ }^{5758}$ and might improve outcome.

We thank the parents of the children, the medical and nursing staff of the intensive care unit, and the consultant neurosurgeons who allowed us to study their patients. We acknowledge financial support from the Newcastle Health Authority, Action Research for the Crippled Child, the Wellcome Trust, the Medical Research Council, and the Mason Medical Foundation.

1 Sharples PM, Storey A, Aynsley-Green A, Eyre JA. Avoidable factors contributing to death of children with head injury. $B M \mathcal{F} 1990 ; 300: 87-91$.

2 Craft AW. Head injury in children. In: Vinken PJ, Bruyn GW, eds. Handbook of clinical neurology. Oxford: Elsevier, 1972;23:445.

3 Bruce DA, Alavi A, Bilaniuk L, et al. Diffuse cerebral swelling following head injuries in children: the syndrome of "malignant brain oedema". $尹$ Neurosurg 1981; 54:170-8.

4 Bruce DA, Raphaely RC, Goldberg AI, et al. Pathophysiology, treatment and outcome following severe head injury in children. Childs Brain 1979;5:174-91.

5 Bruce DA. Cerebrovascular dynamics following brain insults. In: James HE, Anas NG, Perkin RM, eds. Brain insults in infants and children. London: Grune and Stratton Inc, 1985:83-8.

6 Burke AM, Quest DO, Chien S, et al. The effects of mannitol on blood viscosity. F Neurosurg 1981;55:550-3.

7 Bruce DA. Delayed deterioration of consciousness after trivial head injury in childhood. BMF 1984;289:715-6.

8 Hayward R. Management of children with head injuries in district general hospitals. Arch Dis Child 1987;62: 1283-6.

9 Pascucci RC. Head trauma in the child. Intensive Care Med 1988;14:185-95.

10 Muizelaar JP, Marmarou A, DeSalles AAF, et al. Cerebral blood flow and metabolism in severely head injured children. Part 1: Relationship with GCS score, outcome, ICP and PVI. $f$ Neurosurg 1989;71:63-71.

11 Swedlow D, Frewen T, Watcha M, Bruce DA. Cerebral blood flow, AJVDO2 and CMRO2 in comatose children. In: Go KG, Baethmann A, eds. Brain edema. New York: Plenum Press, 1984:365-72.

12 Graham DI, Ford I, Hume Adams J, et al. Fatal head injury in children. $\mathcal{F}$ Clin Pathol 1989;42:18-22.

13 Teasdale G, Jennett B. Assessment of coma and impaired consciousness. Lancet 1974;ii:81-4.

14 Luerssen TG, Klauber MR, Marshall LF. Outcome from head injury related to patient's age. $\mathcal{F}$ Neurosurg $1988 ; 68$ : 409-16.

15 James HE, Trauner DA. The Glasgow coma scale. In: James HE, Anas NG, Perkin RM, eds. Brain insults in infants and children. London: Grune and Stratton infants and $1985: 179-82$.

16 Miller JD, Butterworth JF, Gudeman SK, et al. Further experience in the management of severe head injury. $\mathcal{F}$ Neurosurg 1981;54:289-99.

17 Eyre JA, Oozeer RC, Wilkinson AR. Diagnosis of neonatal seizure by continuous recording and rapid analysis of the electroencephalogram. Arch Dis Child 1983;58:787-90.

18 Berger MS, Pitts LH, Lovely M, Edwards MSB, Bartkowski HM. Outcome from severe head injury in children and adolescents. F Neurosurg 1985;62:194-9.

19 Tasker RC, Matthew DJ, Helms P, Dinwiddie R, Boyd S. Monitoring in non-traumatic coma. Part I: invasive
intracranial measurements. Arch Dis Child 1988;63: 888-94.

20 Kety SS, Schmidt CF. The nitrous oxide method for the quantitative determination of cerebral blood flow in man: theory, procedure and normal values. $f$ Clin Invest 1948;27:476-83.

21 Sharples PM, Stuart AG, Aynsley-Green A, et al. A practical method of serial bedside measurement of cerebral blood flow and metabolism in children receiving neurointensive care. Arch Dis Child 1991;66:1326-32.

22 Benumof $\Omega L$. Respiratory physiology and respiratory function during anaesthesia. In: Miller RD, ed. Anaesthesia. vol 2. 2nd ed. New York: Churchill Livingstone, 1986: $1115-63$.

23 Chambers IR, Mendelow AD, Sinar EJ, Modar P. A clinical evaluation of the camino subdural screw and ventricular monitoring kits. Neurosurgery 1990;26:421-3.

24 Settergren G, Linblad BS, Persson O. Cerebral blood flow and exchange of oxygen, glucose, ketone bodies, lactate, pyruvate and amino acids in anaesthetised children. Acta Paediatr Scand 1980;69:457-65.

25 Bruce DA, Langfitt TW, Miller JD, et al. Regional cerebral blood flow, intracranial pressure and brain metabolism in comatose patients. $\mathcal{F}$ Neurosurg 1973;38:131-44.

26 Obrist WD, Gennarelli TA, Segawa H, Dolinskas CA, Langfitt TW. Relation of cerebral blood flow to neurological status and outcome in head-injured patients. $\mathcal{f}$ Neurosurg 1979;51:292-300.

27 Langfitt TW, Obrist WD, Gennarelli TA, O’Connor MJ, Ter Weeme CA. Correlation of cerebral blood flow with outcome in head injured patients. Ann Surg 1977;186: 411-4.

28 Cold GE, Jensen FT. Cerebral blood flow in the acute phase after head injury. Part 1: correlation to age of the patients, clinical outcome and localisation of the injured region. Acta Anaesth Scand 1980;24:245-51.

29 Christensen MS. Acid-base changes in cerebrospinal fluid and blood, and blood volume changes following prolonged hyperventilation in man. Br $\mathcal{f}$ Anaesth 1974;46: 348-57.

30 Raichle F, Plum F. Hyperventilation and cerebral blood flow. Stroke 1972;3:566-75.

31 Levasseur JE, Wei EP, Kontos HA, et al. Responses of pial arterioles after prolonged hypercapnia and hypoxia in the awake rabbit. F Appl Physiol 1979;46:89-95.

32 McDowall DG, Harper AM. CBF and CSF pH in the monkey during prolonged hypocapnia. Scand $\mathcal{F}$ Lab Clin monkey during prolonged hyp

33 Severinghaus JW, Chiodi H, Eger EI, et al. Cerebral blood flow in man at high altitude. Role of cerebrospinal fluid in normalisation of flow in chronic hypocapnia. Circ Res 1966;19:274-82.

34 Muizelaar JP, Van der Poel, Zhongchao L, Kontos HA, Levasseur JE. Pial arteriolar vessel diameter and $\mathrm{CO}_{2}$ reactivity during prolonged hyperventilation in the rabbit. $\mathcal{F}$ Neurosurg 1988;69:923-7.

35 Sheinberg M, Kanter MJ, Robertson CS, et al. Continuous monitoring of jugular venous oxygen saturation in head injured patients. $\mathcal{F}$ Neurosurg 1992;76:212-7.

36 Obrist WD, Langfitt TW, Jaggi JL, et al. Cerebral blood flow and metabolism in comatose patients with acute head injury. Relationship to intracranial hypertension. $\mathcal{f}$ Neurosurg 1984;61:241-53.

37 Enevoldson EM, Cold G, Jensen FT. Dynamic changes in regional $\mathrm{CBF}$, intraventricular pressure, $\mathrm{CSF} \mathrm{pH}$ and regional $\mathrm{CBF}$, intraventricular pressure, $\mathrm{CSF} \mathrm{pH}$ and
lactate levels during the acute phase of head injury. $f$ lactate levels during the acure
Neurosurg 1976;44:191-214.

38 Messeter K, Nordstrom CH, Sundbarg G, et al. Cerebral haemodynamics in patients with acute severe head trauma. F Neurosurg 1986;64:231-7.

39 Bouma GJ, Muizelaar JP, Choi SC, Newlon PG, Young HF. Cerebral circulation and metabolism after severe traumatic brain injury: the elusive role of ischaemia. $\mathcal{F}$ Neurosurg 1991;75:685-93.

40 Nilsson B, Ponten U. Experimental head injury in the rat. Part 2. Regional brain energy metabolism in concussive trauma. F Neurosurg 1977;47:252-61.

41 Nelson SR, Lowry OH, Passoneau JV. Changes in energy reserves in mouse brain associated with concussive head injury. In: Caveness WF, Walker AE, eds. Head injury. Philadelphia: JB Lippincott, 1966;444-7.

42 Duckrow RB, LaManna JC, Rosenthal M, Levasseur JE Patterson JL. Oxidative metabolic activity of cerebral cortex after fluid percussion injury in the rat. $\mathcal{f}$ Neurosurg cortex after fluid

43 Yoshino A, Hovda DA, Kawamata T, Katayma Y, Becker DP. Dynamic changes in local cerebral glucose utilisation following cerebral concussion in rats; evidence of a hyper- and subsequent hypometabolic state. Brain Res 1991;561:106-19.

44 Kuroda Y, Inglis FM, Miller JD, et al. Transient glucose hypermetabolism after acute subdural haematoma in the rat. $\mathcal{F}$ Neurosurg 1992;76:471-7.

45 Michenfelder JD. Narcotics. In: Michenfelder JD, ed. Anesthesia and the brain. London: Churchill Livingston 1988;113-21.

46 Bruce DA. Ventilation, hyperventilation, megaventilation, and cerebral blood flow. In: James HE, Anas NG, Perkin RM, eds. Brain insults in infants and children. London: Grune and Stratton, 1985:83-8.

47 Yang MS, DeWitt DS, Becker DP, et al. Regional brain metabolite levels following mild experimental injury in metabolite levels following mild exp

48 Vink cat. F Neurosurg 1985;1:297-311. characterisation of graded traumatic brain injury in rats. Magn Reson Med 1988;6:37-48.

49 Rehncrona S, Rosen I, Siesjo BK. Brain lactic acidosis and ischaemic cell damage: 1 . Biochemistry and neurophysiology. F Cereb Blood Flow Metab 1981;1:297-311. 
50 Rehncrona S, Mela L, Siesjo BK. Recovery of brain mitochondrial function in the rat after complete and incomplete cerebral ischaemia. Stroke 1979;10:437-46.

51 Kurup CKR, Kumaroo KK, Dutka AJ. Influence of cerebral ischaemia and post-ischaemic reperfusion on mitochondrial oxidative metabolism. Fournal of Bioenergetics and Biomembranes 1990;22:61-80.

52 Linn F, Paschen W, Grosse Ophoff B, Hossman KA Mitochondrial respiration during recirculation after proMinged ischaemia in cat brain. Exp Neurol 1987;96: 321-33.

53 Wagner KR, Kleinholz M, Myers RE. Delayed decrease in specific brain mitochondrial electron transfer activities specific brain mitochondrial electron transfer activities and cytochrome concentrations followin

54 Wagner KR, Kleinholz M, Myers RE. Delayed onset of neurologic deterioration following anoxia-ischaemia coincides with appearance of impaired brain mitochon- drial respiration and decreased cytochrome oxidase activity. $\mathcal{F}$ Cereb Blood Flow Metab 1990;10:417-23.

55 Robertson CS, Grossman RG, Goodman JC, Narayan RK. The predictive value of cerebral anaerobic metabolism with cerebral infarction after head injury. f Neurosurg 1987;67:361-8.

56 Robertson CS, Narayan RK, Gokaslan ZL, Pahwa R, Grossman RG, Caram P, Allen E. Cerebral arteriovenous oxygen difference as an estimate of cerebral blood flow in comatose patients. $\mathcal{f}$ Neurosurg 1989;70:222-30.

57 Takeo S, Miyake K, Minematsu R, Tanonaka K, Konsh $M$. In vitro effect of naftidrofuryl oxalate on cerebral mitochondria impaired by microsphere-induced embolism in rats. F Pharmacol Exp Ther 1989;248:1207-14.

58 Ferrari R Ceconi C, Curello S, Pasini E, Visioli O. Protective effect of propionyl-L-carnitine against ischaemia tive effect of propionyl- $L$. Mol Cell Biochem 1989;88: 161-8.

\section{NEUROLOGICAL STAMP}

\section{Humulus lupulus (hop)}

The hop plant (Humulus lupulus) is a climbing vine of the hemp family of which cannabis is also a well known member. It has grown wild since ancient times in Europe, Asia, and America. From early antiquity its young shoots were eaten as a vegetable and its dried cone was used for its slightly narcotic effect to produce a sedation against mania, toothache, earache, and neuralgia. Hops were not commonly employed in beer making until the 14 th century when they were used by the Dutch. In England the plant was looked on as an unwholesome weed that promoted melancholy and Henry VI and Henry VIII prohibited its use during their reigns in the 15th and 16 th centuries. It was not until the 17 th century that hops gained acceptance in England, both as an ingredient of beer and as a medicinal herb. A writer noted that the herb "preserves the drink, indeed, but replays the pleasure in tormenting diseases and a shorter life". In the late 19th century, hops were being recommended as a diuretic, a tonic, and a sedative.

The hop, along with other medicinal flowers, is shown on a stamp of Yugoslavia issued in 1955 (Stanley Gibbons 792, Scott 424).

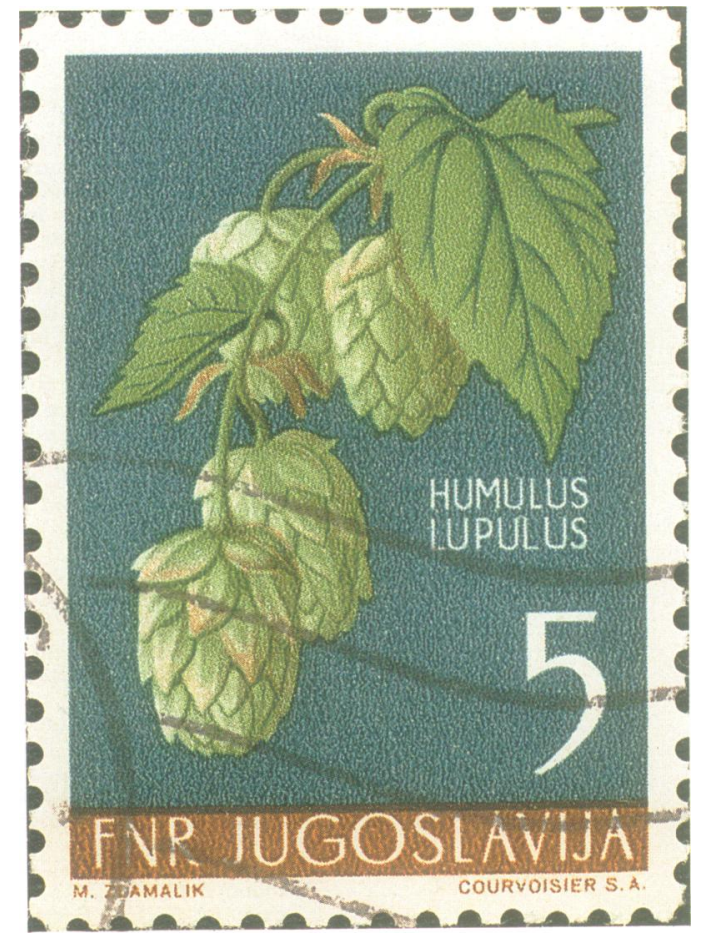

